[Letter]

\title{
Nickel(II)-Catalyzed Ethylation of Cycloalkane via Thermal C-H Bond Activation
}

Yuki Taniguchi, Ko-ichi Satoh, Shiro Horic, Kazuyuki Nakata, Ken Takaki, and Yuzo Fujiwara

Department of Applied Chemistry, Faculty of Engineering, Hiroshima University,

1-4-1 Kagamiyama, Higashi-Hiroshima 724

(Received August 25, 1993)

Nickel chloride catalyzes the ethylation of cyclohexane with ethylene to give cthylcyclohexane via thermal $\mathrm{C}-\mathrm{H}$ bond activation. This ethylation procecds catalytically with turnover number 31 .

Alkane activation/functionalization under mild conditions is one of the most challenging fields of modern chemistry 1). Recently, we reported the palladium-catalyzed carboxylation of alkanes such as cyclohexane 2 ), propane 3$), 4)$, ethane, and methane 4 ).

Alkylation of cycloalkanes with olefins via $\mathrm{C}-\mathrm{H}$ bond activation is very difficult, and drastic reaction conditions are required. Tanaka $e t$ al. reported the rhodium-catalyzed reaction of cyclooctane with ethylene under severe reaction conditions to give ethylcyclooctane and cyclooctene ${ }^{5)}$.

In our continuing work on $\mathrm{C}-\mathrm{H}$ bond activation, we investigated the reaction of cycloalkanes with ethylene using transition metal complex catalysts. We have found that the reaction of cyclohexane with ethylene (10 atm) gives the corresponding ethylcyclohexane (1) in a high turnover of $\mathrm{NiCl}_{2}$ catalyst under mild reaction conditions

(Eq. (1)). We report here these results.

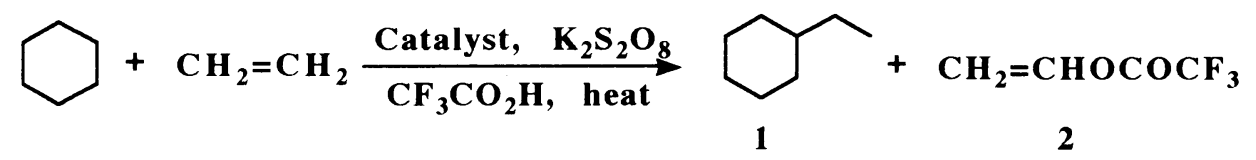

First, we examined the reaction of cyclohexane $(5 \mathrm{ml})$ with ethylene $(10 \mathrm{~atm})$ using various transition metals $(0.2 \mathrm{mmol})$ as catalyst and $\mathrm{K}_{2} \mathrm{~S}_{2} \mathrm{O}_{8}(9 \mathrm{mmol})$ as oxidant in trifluoroacetic acid (TFA, $\left.3.3 \mathrm{~m} l\right)$ in a 100 - $\mathrm{m} l$ stainless steel autoclave with stirring for $20 \mathrm{~h}$ at $120^{\circ} \mathrm{C}$. From this reaction, there were obtained ethylcyclohexane (1) along with vinyl trifluoroacetate (2) derived from the reaction of ethylene with TFA and small amounts of oligomers. The formation of vinyl trifluoroacetate (2) by transition metal catalysis is well known 6 ). The representative results are summarized in Table 1. Other unknown products were also formed in the case of palladium catalysts such as $\mathrm{PdCl}_{2}$ and $\mathrm{Pd}(\mathrm{OAc})_{2}$ (Entries 1 and 2, Table 1). The best result with $\mathrm{Ni}(\mathrm{OAc}) 2$ catalyst was obtained at $10 \mathrm{~atm}$ of ethylene pressure and $120^{\circ} \mathrm{C}$ of reaction temperature (Entry 7 , Table 1). Higher ethylene pressure and reaction temperature resulted in the complicate polymerization of ethylene, and the yield of ethylcyclohexane decreased. The catalytic activity under the same reaction conditions $\left(120^{\circ} \mathrm{C}, 10 \mathrm{~atm}\right)$ has been found to be in the order $\mathrm{NiCl}_{2}>\mathrm{CoCl}_{2} \sim \mathrm{WCl}_{6}>\mathrm{NiBr}_{2} \sim \mathrm{Ni}(\mathrm{OAc}) 2 \sim \mathrm{NiO}_{2}>\mathrm{FeCl}_{2}$ $>\mathrm{MnCl}_{2} \sim \mathrm{SnCl}_{2} \sim \mathrm{Co}(\mathrm{OAc})_{2} \sim \mathrm{Mn}(\mathrm{OAc})_{2}$. In particular, the $\mathrm{NiCl}_{2} / \mathrm{K}_{2} \mathrm{~S}_{2} \mathrm{O} 8$ system gives both higher yield of 
ethylcyclohexane and selectivity (Entry 11, Table 1). In addition, the yield of ethylcyclohexane increased from $294 \%$ to $414 \%$ (based on $\mathrm{Ni}$ ) when the temperature of the mixture was elevated quickly to $120^{\circ} \mathrm{C}$ by using an oil bath previously heated (quick heating method). As is apparent from Table 1, metal chloride catalysts seem to

Table 1 Transition Metal Catalyzed Ethylation of Cyclohexane ${ }^{a}$

\begin{tabular}{|c|c|c|c|c|c|}
\hline Entry & Catalyst & $\begin{array}{l}\text { Temp, } \\
{ }^{\circ} \mathrm{C}\end{array}$ & $\begin{array}{l}\text { Ethylene } \\
\text { Press, atm }\end{array}$ & $1^{\mathrm{b}}$ Yield, & $\mathbf{2}^{\mathrm{c}}$ \\
\hline 1 & $\mathrm{Pd}(\mathrm{OAc})_{2}$ & 80 & 20 & 0.1 & $-d$ \\
\hline 2 & $\mathrm{PdCl}_{2}$ & 80 & 20 & $\mathbf{t r}^{\mathbf{e}}$ & d \\
\hline 3 & $\mathrm{Ni}(\mathrm{OAc})_{2}$ & 80 & 10 & 33 & 0.20 \\
\hline 4 & & 80 & 20 & 9 & 1.25 \\
\hline 5 & & 80 & 50 & 1 & 0.03 \\
\hline 6 & & 100 & 20 & 79 & 0.32 \\
\hline 7 & & 120 & 10 & 160 & 0.60 \\
\hline 8 & & 120 & 20 & 120 & 0.64 \\
\hline 9 & & 140 & 20 & 50 & 0.44 \\
\hline 10 & none & 120 & 10 & - & 0.43 \\
\hline 11 & $\mathrm{NiCl}_{2}$ & 120 & 10 & $294(414)^{f}$ & $0.14(0.23)^{f}$ \\
\hline 12 & $\mathrm{CoCl}_{2}$ & 120 & 10 & 201 & 0.03 \\
\hline 13 & $\mathrm{WCl}_{6}$ & 120 & 10 & 195 & 0.52 \\
\hline 14 & $\mathrm{FeCl}_{2}$ & 120 & 10 & 167 & 0.21 \\
\hline 15 & $\mathrm{NiBr}_{2}$ & 120 & 10 & 160 & 0.60 \\
\hline 16 & $\mathrm{NiO}$ & 120 & 10 & 157 & 0.18 \\
\hline 17 & $\mathrm{MnCl}_{2}$ & 120 & 10 & 146 & 0.23 \\
\hline 18 & $\mathrm{SnCl}_{2}$ & 120 & 10 & 140 & 1.18 \\
\hline 19 & $\mathrm{Co}(\mathrm{OAc})_{2}$ & 120 & 10 & 139 & 0.02 \\
\hline 20 & $\operatorname{Mn}(\mathrm{OAc})_{2}$ & 120 & 10 & 134 & 0.82 \\
\hline 21 & $\mathrm{NiF}_{2}$ & 120 & 10 & 127 & 0.63 \\
\hline 22 & $\mathrm{CrCl}_{3}$ & 120 & 10 & 125 & 2.25 \\
\hline 23 & $\mathrm{Ni}_{2} \mathrm{O}_{3}$ & 120 & 10 & 122 & 0.54 \\
\hline 24 & Ni black & 120 & 10 & 120 & 0.78 \\
\hline 25 & $\mathrm{CoSO}_{4}$ & 120 & 10 & 71 & 0.11 \\
\hline 26 & $\mathrm{NiSO}_{4}$ & 120 & 10 & 68 & 0.95 \\
\hline 27 & $\mathrm{MnSO}_{4}$ & 120 & 10 & 21 & $\mathbf{0 . 3 3}$ \\
\hline
\end{tabular}

${ }^{a}$ Cyclohexane $(5 \mathrm{~m} l)$, catalyst $(0.2 \mathrm{mmol}), \mathrm{K}_{2} \mathrm{~S}_{2} \mathrm{O}_{8}(9 \mathrm{mmol})$, TFA $(3.3 \mathrm{~m} l), 20 \mathrm{~h}$. ${ }^{b}$ GC yield based on catalyst. ${ }^{\mathrm{c}} \mathrm{GC}$ yield based on TFA. ${ }^{\mathrm{d}} \mathrm{A}$ large amount of unknown products were formed. ${ }^{\mathrm{e}}$ Trace amount. 'Quick heating.

be somewhat effective for the reaction. But the addition of chloride ion sources such as $\mathrm{NaCl}, \mathrm{KCl}$, and $\mathrm{LiCl}$ to $\mathrm{NiCl}_{2}$ was not effective. In contrast to metal chloride catalysts, metal sulfates were inactive in this reaction. The 
yield of ethylcyclohexane (1) increases linearly with reaction time and with the increasing amounts of potassium persulfate $\left(\mathrm{K}_{2} \mathrm{~S}_{2} \mathrm{O}_{8}\right)$, but it decreases with the use of a large excess because of the lower efficiency of stirring. It seems that $\mathrm{K}_{2} \mathrm{~S}_{2} \mathrm{O}_{8}$ abstracts $\mathrm{H} \bullet$ from cyclohexane to give cyclohexyl radical. Use of other radical initiators such as AIBN, tert-butyl perbenzoate and oxidizing agents such as $\left(\mathrm{NH}_{4}\right)_{2} \mathrm{~S}_{2} \mathrm{O}_{8}$, OXONE (2KHSO $5 \mathrm{KHSO}_{4}$. $\mathrm{K}_{2} \mathrm{SO}_{4}$ ) gave inferior results. Trifluoroacetic acid (TFA), a superacid has been found to be the best to accelerate the homolytic radical cleavage of $\mathrm{O}-\mathrm{O}$ bond of $\mathrm{K}_{2} \mathrm{~S}_{2} \mathrm{O}_{8} 7$ ). Other organic acids such as acetic and formic acids and usual organic solvents such as methanol were inactive.

Then, we examined the effect of the amount of $\mathrm{NiCl}_{2}$ catalyst using the quick heating method. These results were listed in Table 2. The turnover number of catalyst increases up to 31 (Entry 4, Table 2) when the amount of $\mathrm{NiCl}_{2}$ is decreased to $0.01 \mathrm{mmol}$, while the yield based on cyclohexane decreases.

Table 2 Effect of the Amount of Nickel Chloride ${ }^{a}$

\begin{tabular}{llrlr}
\hline & & \multicolumn{3}{c}{ Yield, \% } \\
Entry & $\mathrm{NiCl}_{2}(\mathrm{mmol})$ & $1^{\mathrm{b}}$ & $2^{\mathrm{c}}$ \\
\hline 1 & 0.2 & 414 & $(1.7)$ & 0.23 \\
2 & 0.1 & 702 & $(1.4)$ & 0.22 \\
3 & 0.05 & 932 & $(1.1)$ & 0.86 \\
4 & 0.01 & 3131 & $(0.9)$ & 1.91 \\
5 & none & - & & 1.30 \\
\hline
\end{tabular}

${ }^{\mathrm{a} C y c l o h e x a n e}(5 \mathrm{ml})$, ethylene $(10 \mathrm{~atm}), \mathrm{K}_{2} \mathrm{~S}_{2} \mathrm{O}_{8}(9 \mathrm{mmol})$, TFA $(3.3 \mathrm{ml})$, $120{ }^{\circ} \mathrm{C}, 20 \mathrm{~h}$. ${ }^{\mathrm{b}} \mathrm{GC}$ yield based on $\mathrm{Ni}$ (on cyclohexane). ${ }^{\mathrm{c}} \mathrm{GC}$ yield based on TFA.

In order to investigate the reaction mechanism, we attempted the reaction with the use of radical scavenger. The ethylation was inhibited by an addition of 4-tert-butylcatechol, and no ethylation product was obtained.

Ethylation of adamantane was also investigated. In this reaction, 2-ethyladamantane (3) which is derived from ethylation on the secondary carbon of adamantane, was obtained in $178 \%$ yield based on Ni together with 1 ethyladamantane (4, 40\% yield) (Eq.(2)). Use of $0.05 \mathrm{mmol}$ of $\mathrm{NiCl}_{2}$ and $1.0 \mathrm{mmol}$ of $\mathrm{K}_{2} \mathrm{~S}_{2} \mathrm{O}_{8}$ gives ethylada-

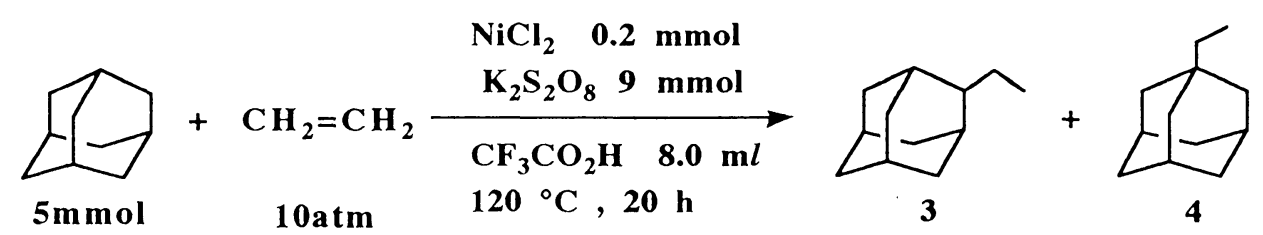

mantanes (3 and 4) in 137 and 35\% yields, respectively. These results show that ethylation on the bridge-head carbon (tertiary C) is difficult. On the other hand, palladium(II)-catalyzed carboxylation of adamantane in which electrophilic attack of cationic Pd species on the bridge-head carbon is most favorable, gave 1- 
adamantanecarboxylic acid $2 a)$. In the present reaction, regiochemistry of the products is the quite opposite to the case of Pd catalyst, showing that the reaction includes radical process.

The mechanism of the nickel-catalyzed ethylation of cyclohexane could be explained as depicted in Scheme

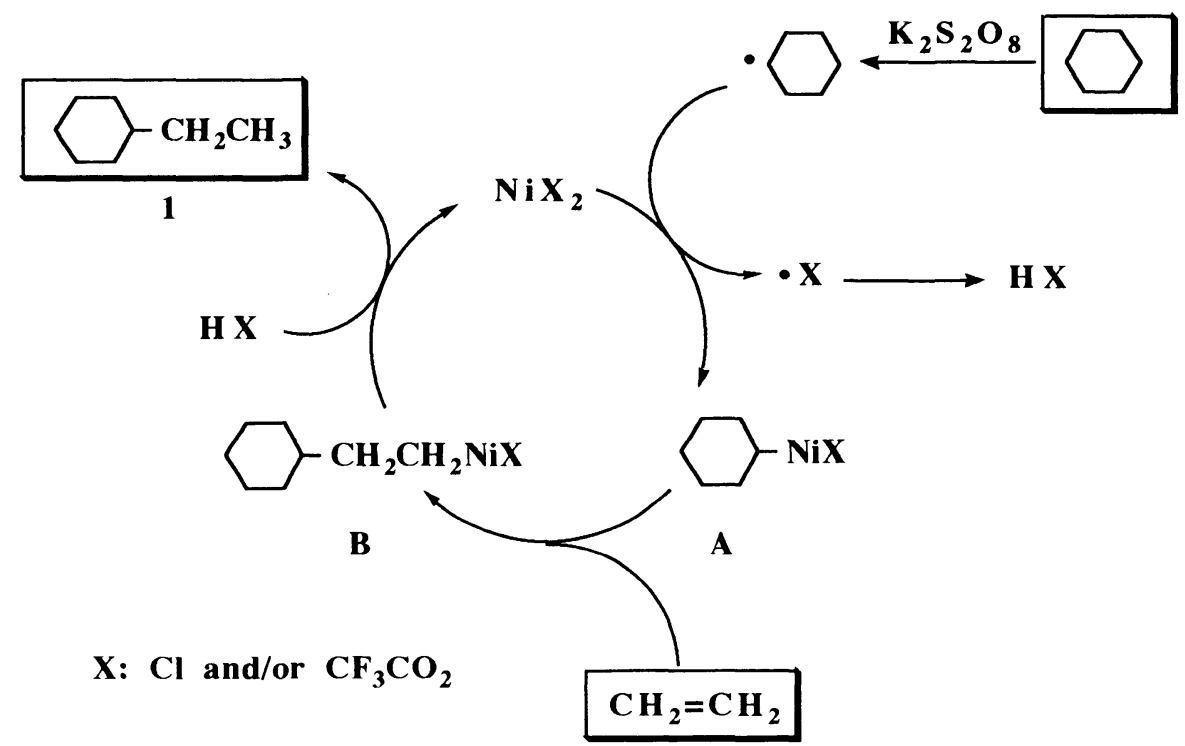

Scheme 1 Reaction Mechanism

1. $\mathrm{K}_{2} \mathrm{~S}_{2} \mathrm{O}_{8}$ acts as a radical initiator under the acidic media of TFA, and abstracts hydrogen radical $(\mathrm{H} \bullet)$ from alkane $\mathrm{C}-\mathrm{H}$ bond to give a cyclohexyl radical. The cyclohexyl radical generated reacts with nickel(II) catalyst to afford a $\sigma$-alkyl nickel(II) complex (A). Then, ethylene insertion followed by solvolysis with TFA yields ethylcyclohexane (1) and nickel(II) catalyst again and thus the catalytic cycle is completed.

\section{References}

1) (a) Fujiwara, Y., Jintoku, T., Takaki, K., CHEMTECH, 20, 636 (1990). (b) Takaki, K., Fujiwara, Y., Kagaku, 46, 80 (1991)

2) (a) Satoh, K., Watanabe, J., Takaki, K., Fujiwara, Y. Chem. Lett., 1433 (1991). (b) Nakata, K., Watanabe, J., Takaki, K., Fujiwara, Y., Chem. Lett., 1437 (1991). (c) Fujiwara, Y., Takaki, K., Watanabe, J., Uchida, Y., Taniguchi, H., Chem. Lett., 1687 (1989).

3) Miyata, T., Nakata, K., Yamaoka, Y., Taniguchi, Y., Takaki, K., Fujiwara, Y., Chem. Lett., 1005 (1993)

4) Nishiguchi, T., Nakata, K., Takaki, K., Fujiwara, Y., Chem. Lett., 1141 (1992).

5) Sakakura, T., Abe, F., Tanaka, M., Chem. Lett., 359 (1991).

6) Heck, R. F., "Palladium Reagents in Organic Syntheses", Academic Press, New York (1985), p. 81-82.

7) Jönsson, L., Wistrand, L.-G., J. Chem. Soc., Perkin Trans. 1, 669 (1979)

\section{Keywords}

Cycloparaffin, Ethylene, Alkylation, Homogeneous catalyst, Nickel chloride, Trifluoroacetic acid 